\title{
AN OVERVIEW OF THE IP POLITICS IN SOFTWARE AND RESEARCH BASED SME COMPANY
}

\section{Barac, M.; KuKOLJ, D.; KuKOLJ, S.; Antin, M. \& TeKiC, Z.}

Abstract: This paper addresses the issue of IP politics and management of the IP assets in software and research based SME company. At the beginning it is presented a brief introduction to the general theme of IP politics in SME companies, then it is described, general and detailed, and at the end some results and case studies of IP asset management in software and research based SME company have been placed and we have dealt with some further steps. Within the general story about IP politics it is mentioned that patents have a main role in IP politics and management and it is explained the workflow concerning maintenance and processing of individual patent applications. It is also provided an overview of some internal issues in IP asset management regarding to the ownership, intangible assets such as: franchises, licenses, contracts, software, know how, etc. After general story about IP politics, it is given an overview of detailed steps concerning internal IP software system with its online database of the patent documents and with many of its modules with different functionalities. In the last section we put the results of these functionalities which are produced by internal IP software system e.g. automatically overview of researchers in relation to the patent application, an overview of the most common technologies in the field of software in relation to the patent applications, many business company projects in relation to the patent applications etc..

Key words: patent, SME, software, research, IP politics
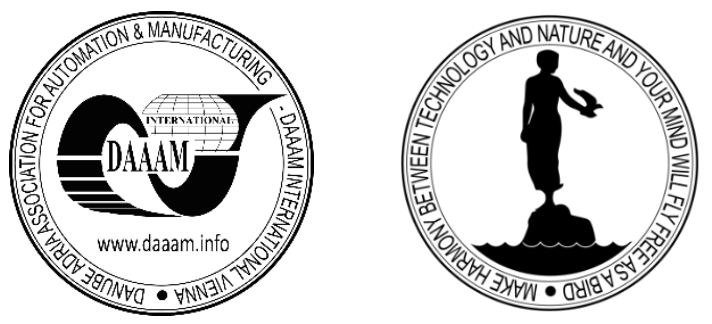

Authors' data: M.Sc. Barac, M[ilana] ${ }^{*}$; Prof.Dr. Kukolj, D[ragan]**; M.Sc. Kukolj, S[andra]*; B.Sc. Antin, M[ilana]*; Ass.Prof.Dr. Tekic, Z[eljko]***, *RT-RK Institute for Computer Based Systems, Narodnog fronta, 23a, Novi Sad, Serbia, ** Faculty of technical sciences, Trg Dositeja Obradovica, 6, Novi Sad, Serbia, ***Skolkovo Institute of Science and Technology (Skoltech), Moscow, Russia milana.barac@rtrk.com,dragan.kukolj@rt-rk.com, sandra.kukolj@rt-rk.com, milana.antin@ rt-rk.com, z.tekic@skoltech.ru.

This Publication has to be referred as: Barac, M[ilana]; Kukolj, D[ragan]; Kukolj, S[andra]; Antin, M[ilana] \& Tekic, Z[eljko] (2015). An Overview of the IP Politics in Software and Research based SME Company, Chapter 13 in DAAAM International Scientific Book 2015, pp.143-152, B. Katalinic (Ed.), Published by DAAAM International, ISBN 978-3-902734-05-1, ISSN 1726-9687, Vienna, Austria DOI: $10.2507 /$ daaam.scibook.2015.13 
Barac, M.; Kukolj, D.; Kukolj, S.; Antin, M. \& Tekic, Z.: An Overview of the IP Po...

\section{Introduction}

In the last decade, management of the intellectual property assets (IP asset management) or IP politics at all, is experiencing real expansion in large giant`s companies of the world's leading industries, but also in small and medium-sized enterprises (SMEs) engaged in propulsive activities relating to the software services: in digital television, multimedia, telecommunications, chips manufacturing, automotive industry etc.

Many authors analyze patents, intellectual property and the management of IP assets. We have found some of the most interesting approaches.

MacDonald (MacDonald, 2004) explains that although it is supposed that the patent is the end of an innovation process, whatever the patent can be regarded, as an effort innovators to protect their product, or simply carry out the dissemination of knowledge, the patent can not constitute the end of the innovation process, it is just beginning of the IP management process.

From the other side Cohen and Nelson (Cohen, et al.,2000) say that the firms typically protect invention with a range of mechanisms, including patents, secrecy, lead time advantages and the use of complementary marketing and manufacturing capabilities. Of these mechanisms, patents tend to be the least emphasized by firms in the majority of manufacturing industries, and secrecy and lead time tend to be emphasized by most heavily. Analyzing the US manufacturing sector during the nineties, the same authors say that firms commonly patent for different reasons in „discrete“ product industries, such as chemicals, versus „,complex“ product industries, such as telecommunications equipment or semiconductors.

Lemley (Lemley, 2008) for example analyzes the patent market and explains that patent market is a blind market, where everything is somehow confidential. He explains that the most appropriate solution is to make patent market to be like a stock exchange with the main aspect to determine whether a patent is valid and what it covers, etc.

Lecorpio (Lecorpio, 2015) with its services gives a great example of IP asset management. They explain some of the main characteristics of IP asset management: comprehensive functionality, workflow and collaboration (to automate all manual operations, reduce duplicate data entry etc.), reporting and analytics (robust analytical and reporting capabilities, set of visualization tools to analyze important metrics to help you conduct historical and comparative trend analysis) and at the end configuration (to optimize certain workflow or preference).

WIPO analyzes the aspect of the monetization of the IP assets which can be done in several ways: direct selling, licensing (e.g. US, Japan, UK as countries and IBM and Dell companies), as a defence of competition or as support of their company budgets and to sustain continued education and research (e.g. Canadian and US Universities), etc. IP assets provide additional security to financiers which new product or service that SME offers is protected by patent. Such protection is a good indicator that some third company invests in our company. For these reasons, it is crucial that SMEs understand the commercial value of its IP assets. For this understanding, it is necessary to set some internal issues within the company (WIPO, 2015), (Vitas et al., 2014). 
According to the Fraunhofer (Frietch et al., 2013) SMEs have been shown to be important sources of employment growth and innovation (Andretsch, 2001) and can be seen as key players in national innovation systems. They also note that in Germany for e.g. 99.3 percent of all companies are SMEs. SMEs employ smaller teams of inventors which indirectly causes fewer costs in invention stage.

With usage of these available literature analyses, in this paper we will try to describe IP politics as more general concept and IP asset management as its simpler form, in research and computer based SME company. IP politics in the SME company, generally refers to the motivation of company itself to generate revenues from product sales, then motivation for engineers and researchers to prove its own benefits, in future also there will be motivation for licensing royalties and motivation to prove market positions. Mentioned IP management refers primary to patent management. In future it could be expected some technology transfer activities to be implemented as well.

SME software and research based company is mainly engaged in services and products related to the software for digital television, multimedia devices, smart homes and since last year automotive industry. In its IP asset management, in a first step, company includes organization of patent related documents into database and managing of budgets and actual costs, which was already mentioned in some papers (Tekic et al., 2012a),(Tekic, 2014) and also will be discussed in the following sections.

\section{General description of the company`s IP department and management}

Within research and software based SME company there is a special IP department which generally deals with in company IP politics and more specifically this department does all activities closed to the IP management. Currently this department is primarily engaged in the patent management system. The system means many activities about creation and organization of the patent database with its modules. The system could be viewed as one workflow with different sections such as: creating patents, patent database maintenance and finally creation strategies related to the management of intellectual property at all.

People in IP department carry a huge and demanding process of researching projects activities, organizing meetings with research teams in company, performing preliminary search analysis based on the idea proposal, creating patent applications and finally they are managing the flow of patent applications and later maintenance the granted patents. All activities include many patent related documents which are centrally organized and can be managed on different ways: analyzing, clustering by technologies and product groups, etc. (Figure 1 below shows a great example of clustering patents according to different technology groups).

Besides these usually patent prosecution and maintenance activities, IP department in the mentioned SME company must set some form of the IP policy. It is well known that IP Policy deals with many issues. First of all it must be defined the ownership of all IP assets. Usually it is SME company itself, or it might be any other company, consortium or individual owners. Within this issue should not be considered only patents, but also some intangible assets e.g. franchises, licenses, contracts, 
Barac, M.; Kukolj, D.; Kukolj, S.; Antin, M. \& Tekic, Z.: An Overview of the IP Po...

software, distribution network, know how, etc. of course, if the company owns such assets.

IP policy also considers the status and maintenance of IP portfolio. This issue means the status of individual patent applications and later granted patents. After these crucial things, it should be analyzed the way how SME company plans to protect its own IP asset portfolio.

In the light of directly impact to the business, the IP assets should be analyzed regarding to different kinds of filters: for example filter for currently used patent applications, or potentially usable and maintained patent applications, but not so useful. Figure 2 and Figure 3, in the section below; give an interesting example of these filters.

At the end, IP asset management politics always has to be aware of its company`s monetization aspect regarding to the assets at all and regarding to the other company`s current and further business steps. The monetization aspect is described in Figure 4 in section below as one case study.

\section{Detailed description of the database software system}

As Lecorpio (Lecorpio, 2015) notes, IP asset management system should measure any information, such as activities, submissions, applications, work time, costs, revenues, etc. It should define reports and charts as well, and it should to recommend best practices.

IP asset management, in software and research based SME company, is service oriented architecture with whose help the company can make a defensive IP strategy (Tekic, 2012b). It includes patents and patent applications generated during the years, then its monitoring of the process and status in which they are, track maintenance costs, etc. It also involves all aspects of patent lifecycle management: idea submission, IP creation, prosecution, enforcement and portfolio management.

The whole software system is composed of online database of patent documents. It is client-server oriented system where client side includes application interface that can represent a standard web browser (e.g. Firefox), and server side includes a web server. Between server and client side, there is network place. Online implementation of database systems might be organized through Knowledge Tree server platform, for example. Server side manages with all patent documents, does analytical functions and generates reports, manages the database and enables entering control and security.

During patenting process, the database always contains several modules which are made using Java technologies, PHP and MySQL as well at PSALM tool (Tekic, 2014). These modules are named: patent ideas module, patent applications module, reports module, etc. The process of generation patent applications starts when the patent ideas come from the researchers. When receiving patent ideas, than in database system patent ideas module starts. At the same time it is necessary to enter following attributes into this module: ideas working title, date of receiving ideas, and the name of engineer who is responsible for the idea, a brief description of the invention concept, keywords to search for state of the art and the result of this search. After receiving the ideas and entering attributes, patent ideas module activates the state of the art search section. The results of this section might be characterized as positive and in that case 
it should not be generated a patent application and the operation stops here until some further idea improvements from researchers or IP engineers. In the case of the search results which are characterized as negative, a patent application should be generated and the patent applications module should be activated.

At the beginning of the writing patent application, this patent applications module generates a folder in which patent documents will be placed, during the patenting process. This folder should contain an application document, state of the art document, special application form, document with the names of inventors and abstract in English. All the documents should have a specific template. When all application documents are sent to the National Intellectual Property Office, it is necessary to input the following attributes into database system: the date of receipt of idea, the number of patent application, the date of submission to the Office, title, title in English, the list of inventors, project name, a brief description of the application, a link to the state of the art document, the number of claims, claims, different links etc. Links to documents describe relationship with documents located in the online folder. All attributes are stored in the database locally and online.

In the database there are also financial tables and tables of the letters that accompanies patent application. The financial table should include: ID of the patent application and several fields for taxes. Table of letters should contain: ID of patent application, the name of the letter, the date of the letter and link to information $\mathrm{N}(\mathrm{N}=$ $1, \ldots 15)$. Letters are actually documents that arrive from National Patent Office in the process of patent granting.

Besides these mentioned forms, database system must contain update attribute as a form of correspondence between our department and National IP Office. When updating the technical data, in a patent application folder should be generated a subfolder with a date (e.g. update_15032015). During the update process, some database fields should be changed, but also generated a new fields (e.g. granted patent number, the person in charge in the Office, publication date and number of the Official Gazette where it is published, etc.).

In database system there are also reports filtered by various criteria. Next section will show some of the interesting reports.

\section{An illustrative case studies}

Through the all figures in this paper it was tried to present one example of IP Management in software and research based SME company.

Figure 1 shows the results of report module. Patent applications and patents are filtered regarding to technologies which are given via IPC group names. Based from this graph it is visible that the largest groups are: IPC classification H04N17 Diagnosis, testing or measuring for television systems group, H05B41- Circuit arrangements or apparatus for igniting or operating discharge lamps group, G06F9Arrangements for programme control e.g. control unit group, etc.). 
Barac, M.; Kukolj, D.; Kukolj, S.; Antin, M. \& Tekic, Z.: An Overview of the IP Po...

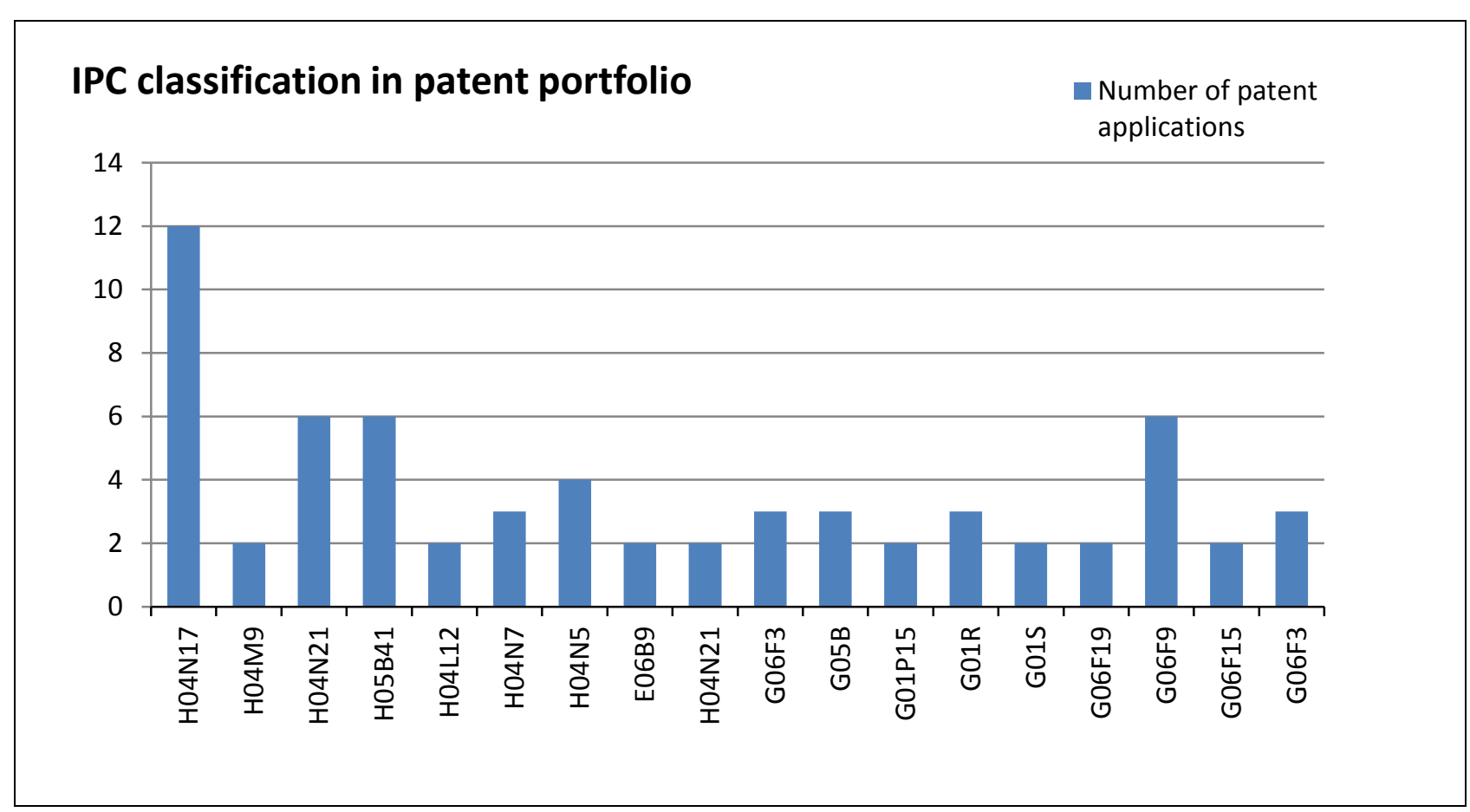

Fig. 1. Patents clustering

Figure 2 presents another filter according to period of time. In this graph are presented all patent applications with granted patents over the years, since 2006.

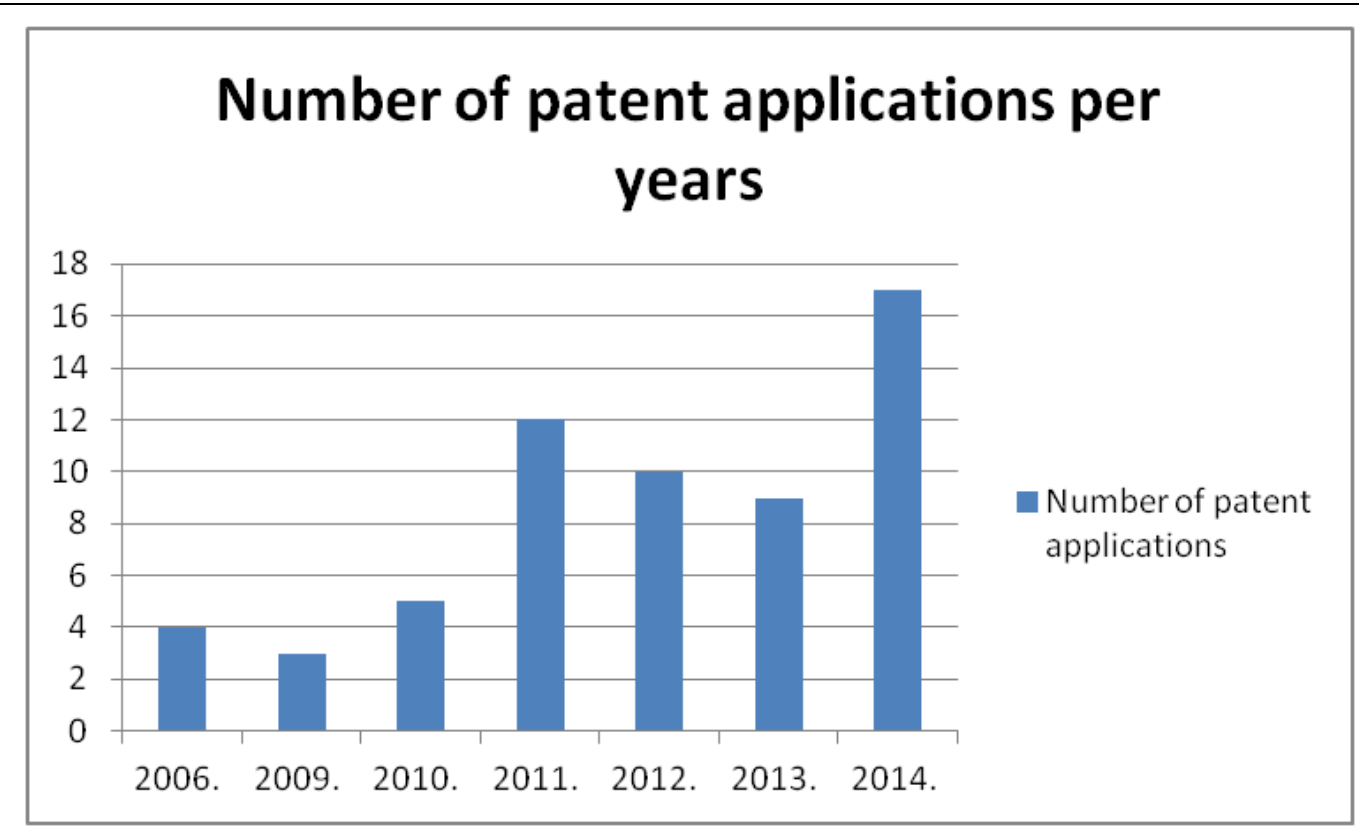

Fig. 2. Research and computer based SME company-the total number of patent applications/granted patents over the years

Figure 2 gives the overview of generated patent applications in the period of 20062014. It can be seen that 2011 and 2014 years are the most productive years considering the number of patent applications. Also last 3-4 years have a good production of patent applications. 


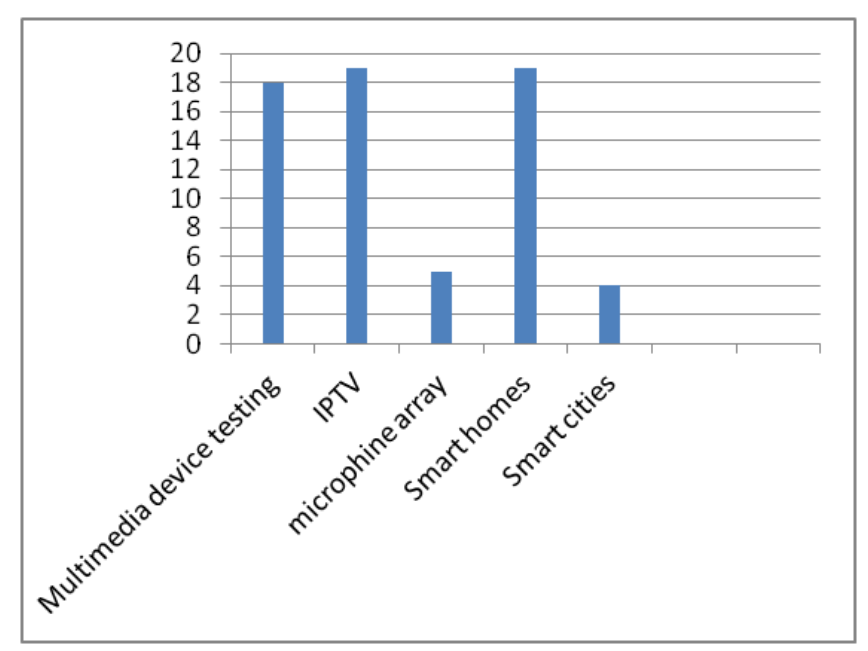

Fig. 3. The total number of patent applications/granted patents per projects

Figure 3 is third kind of filter according to the company`s projects. It has the aim to identify the number of patent applications and granted patents per projects. There are 3 active projects: Multimedia device testing project, IPTV project and smart homes project. Other projects were finished. IP asset management involves their patents too, but only their maintenance, not future generation of the new patent applications. From this graph it is visible that these mentioned three active projects provide the most patent applications and it is expected, considering the fact that the most number of researchers and employees work within them.

Figure 2 and Figure 3 show the productivity and growth of whole company's patent portfolio. It can be concluded that 2014 year is the most productive year and also Multimedia device testing project, IPTV project and smart homes project provide the most patent applications in recent years.

Figure 4 presents some of the costs per projects, just as an illustrative example.

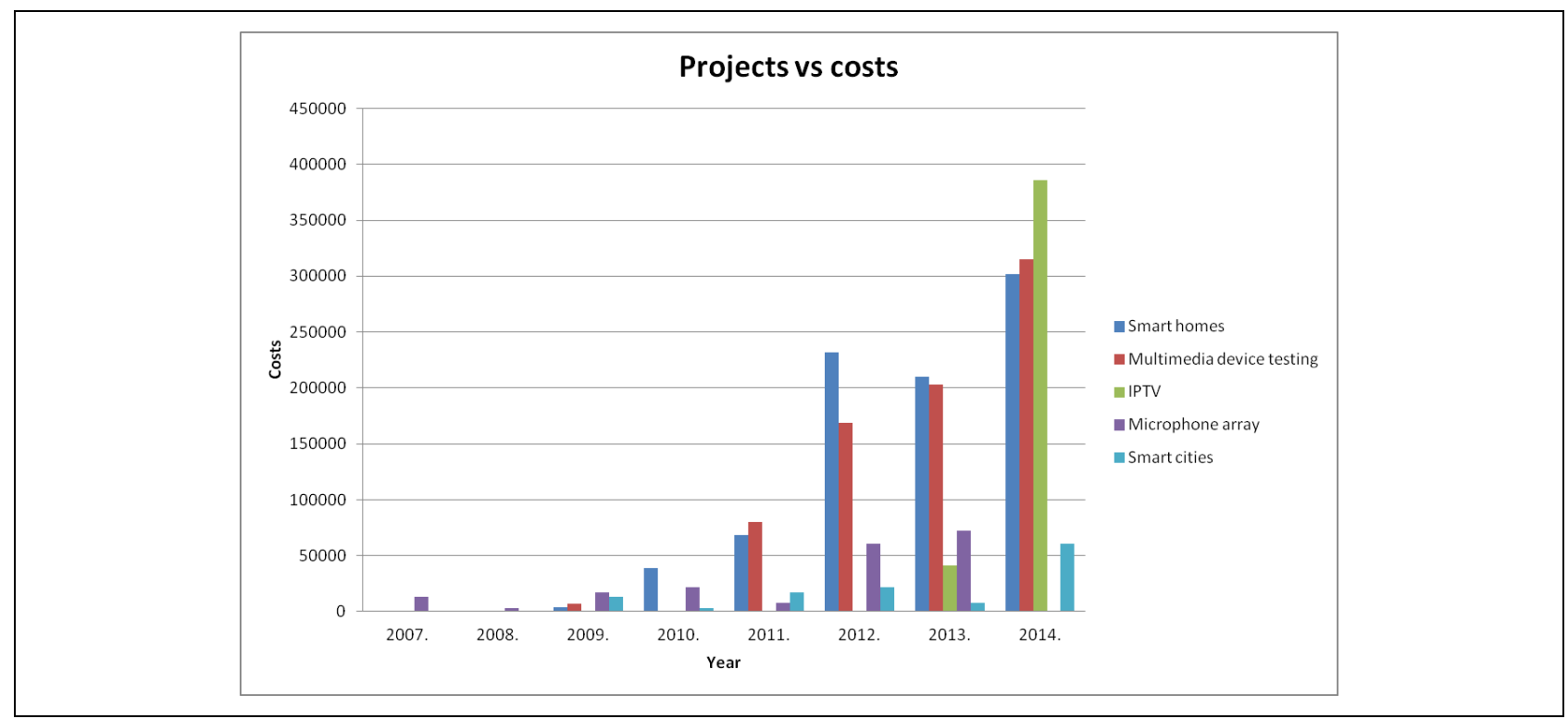

Fig. 4. IP asset management- costs per projects 
Barac, M.; Kukolj, D.; Kukolj, S.; Antin, M. \& Tekic, Z.: An Overview of the IP Po...

In Figure 4 it is given an overview of maintenance costs for patent applications per projects. During 2007 and 2008 there are related costs to Microphone array project which practically is not active. For 2012, 2013 and 2014, all projects reflect a cost accumulation. In 2014 only, these costs are between 2500 and 3500 euro for Smart homes project, Multimedia device testing project and IPTV project, cumulatively.

Figure 5 reflects the patenting work from the side of inventors. Most often the inventors are junior and/or senior researchers which are marked from the IP engineers as appropriate persons for making something new and innovative from the point of patenting. Most junior patent researchers possess one patent application; something less them have 2 patent applications, but rarely 3 or more. Also from this graph in Figure 5 it can be concluded that there are senior researchers who have 14, or 18 patent applications and granted patents and it is very logical because their research work have been accumulated during the years.

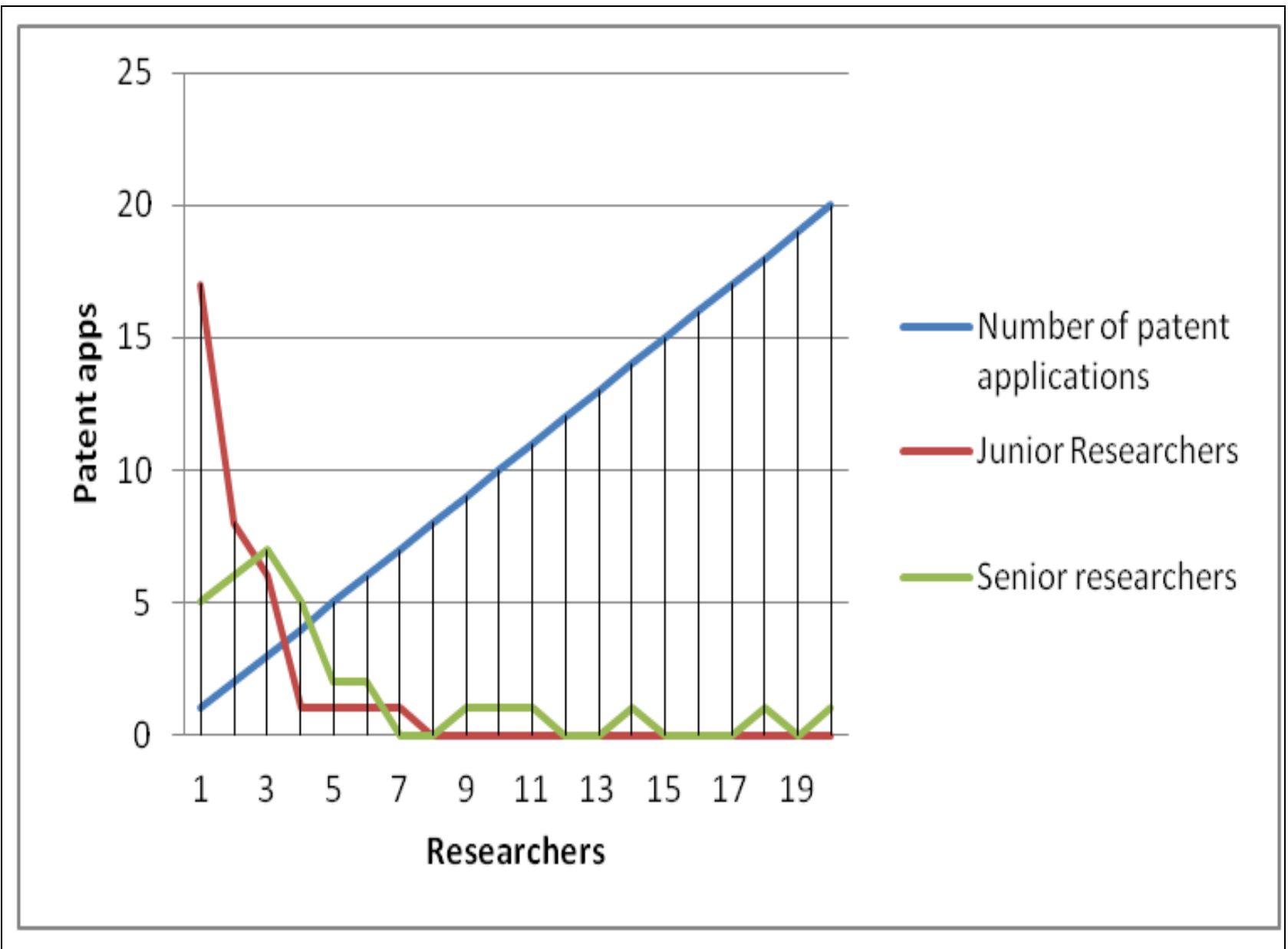

Fig. 5. Patents applications vs junior/senior researchers

At the end of these presented an illustrative case studies, it is presented the number of correspondences between IP Department and National IP Office. These correspondences are named updates and Figure 6 shows the number of updates per each granted patent. Usually this number varieties between one and three updates for each granted patent. 


\section{Granted patents vs updates}

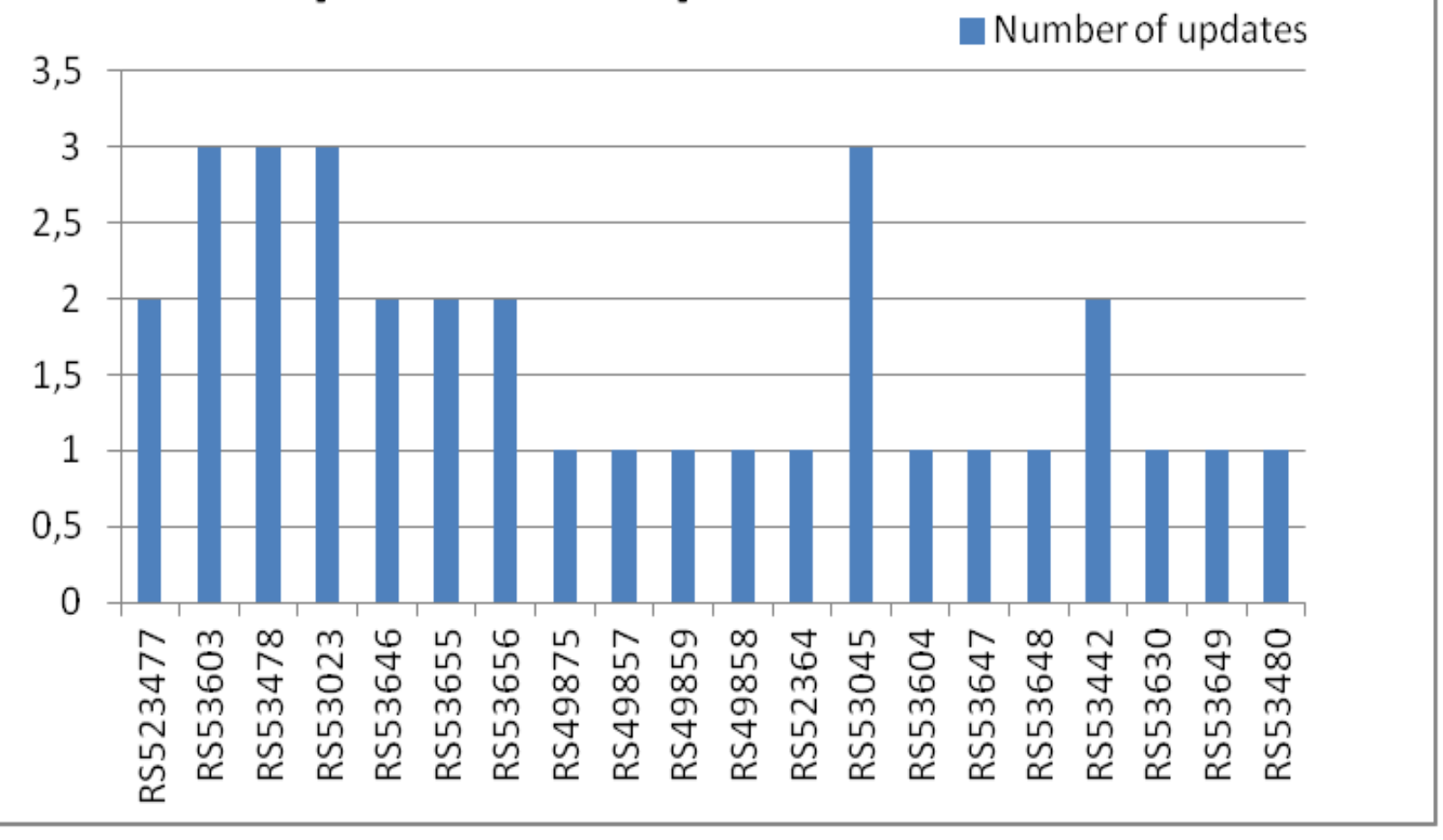

Fig. 6. Updates-correspondences with National IP Office

\section{Conclusion}

In this paper, the IP Management activities of one software and research based SME company were analyzed. In a first step, a quick overview of the IP management activities is given, generally, after that some details about the database software system are presented and at the end the internal SME patent portfolio was analyzed through the presented graphs.

For some further steps it can be expected the growth of the SME company at all, and the development of IP asset management as well. Also in the near future it will be evident increase of all IP costs, because there will be more projects in company and of course new patent applications. From the other side it must not be forgotten costs from maintenance of the existing patent applications which will be accumulated over the years. IP asset management should involve the aspect of potentially valuable patent applications which should have priority over others because of their commercially aspect.

Regarding to the mentioned database system, update work should introduce some statistical aspect of tracking and maintenance patent applications and granted patents. For example it should be developed the new statistical module for automatically calculating the following attributes: parameters related to the statistics of time it takes for preparation of patent applications, statistics monitoring the duration of processing the application in the Office, statistics monitoring costs for the some patent, statistics idea proposed by author and many other relevant patent data. 
Barac, M.; Kukolj, D.; Kukolj, S.; Antin, M. \& Tekic, Z.: An Overview of the IP Po...

\section{Acknowledgements}

This work was partially supported by the Ministry of Education, Science and Technology Development of the Republic Serbia under Grant number TR-32034, III44009; and by the Provincial secretary of Science and Technology Development of Vojvodina Province under Grant number 114-451-2434/2011-03.

\section{References}

MacDonald, S. When means become ends: considering the impact of patent strategy on inovation. Information Economics and Policy 2004: 16(1): pp. 135-158

Cohen, W. M.; Nelson R. R.; Walsh J. P. Protecting their intellectual assets: appropriability conditions and why firms patent or not? Cambridge 2000., MA:NBER Working Paper No. 7552

Lemley, M.; Myhrvold, N. How to make a patent market. Hofstra Law Review 2008: 36: pp. 257-259

http://www.lecorpio.com/products/ -Lecorpio IP Management Software , Accessed on:2015-03-02

http://www.wipo.int/edocs/pubdocs/en/intproperty/896/wipo_pub_896.pdf -WIPO-IP Asset Development and Management: A Key Strategy for Economic Growth-WIPO Publication No 896E, ISBN 978-92-805-1562-6, Accessed on: 2015-03-02

Vitas, M.; Kukolj, D.; Drazic, M.; Tekic, Z. \& Kukolj, S. (2014). The development of an appropriate framework of IP Management. Proceedings of $6^{\text {th }}$ International Scientific Conference on Defensive Technologies, OTEH, Belgrade, 2014

Frietsch, R.; Neuhäusler, P.; Rothengatter, O. Fraunhofer ISI Discussion Papers Innovation Systems and Policy Analysis No. 36, SME Patenting - An Empirical Analysis in Nine Countries, ISSN 1612-1430, Karlsruhe, October 2013

Audretsch, D.B. (2001): The Dynamic Role of Small Firms: Evidence from the U.S. Washington, D.C. The International Bank for Reconstruction and Development/The World Bank

Tekic, Z.; Drazic, M.; Kukolj, D.; Vitas, M. (2014). From patent data to business intelligence - PSALM case studies, // Procedia Engineering 69 (2014), Katalinic, B. (Ed.), pp. 296 - 303, Zadar, 2014

Tekic, Z.; Kukolj, D.; Nikolic, Lj.; Drazic, M.; Pokric, M.; Vitas, M.; Panjkov, Z.;\& Nemet, D. (2012a). PSALM - Tool for business intelligence. Proceedings of 35th MIPRO - International convention on information and communication technology, electronics and microelectronics, pp. 1975-1980, Opatija, Croatian Society for Information and Communication Technology, Electronics and Microelectronics MIPRO, 2012

Tekic, Z.; Kukolj, D.; Nikolic, Lj.; Pokric, M.; Drazic, M.; Vitas, M.; (2012b). SMEs, patent data and new tool for business intelligence. Proceedings of $5^{\text {th }}$ International Conference for Entrepreneurship, Innovation and Regional Development ICEIRD, pp.855-863, Sofia, St.Kliment Ohridski University Press, 2012 